Pacific Journal of Mathematic 


\section{CERTAIN CLASSES OF REGULAR UNIVALENT FUNCTIONS}

\section{KARUNAKARAN}

If $f(z)$ and $g(z)$ are starlike functions of orders $\alpha$ and $\gamma$ for $\alpha, \gamma \in[0,1)$, then it is shown that

$$
F(z)=\frac{2}{g(z)} \int_{0}^{z} f(t) d t
$$

is $\beta$-starlike for $|z|<\delta$, where $\delta$ is a function of $\alpha, \beta, \gamma$. Conversely, a sharp estimate is obtained for the radius of $\beta$-starlikeness of the class of functions

$$
f(z)=2^{-1}(g(z) F(z))^{\prime},
$$

where $g(z)$ and $F(z)$ are starlike functions of orders $\gamma$ and $\alpha$ respectively, with $\alpha+\gamma \leqq 1$.

Let $S$ denote the family of functions $f(z)$ which are regular and univalent in the unit disc $E$ of the complex plane and which satisfy the conditions $f(0)=0=f^{\prime}(0)-1$. Let $S^{*} \subset S$ denote the class of starlike functions, namely those members of $S$ which map $E$ onto a domain that is starlike with respect to the origin. Libera [2] showed that if $f(z) \in S^{*}$, then

$$
F(z)=\frac{2}{z} \int_{0}^{z} f(t) d t
$$

also belongs to $S^{*}$. In the converse direction, Livingston [4] has studied the mapping properties of the function

$$
f(z)=2^{-1}(z F(z))^{\prime}
$$

where $F(z) \in S^{*}$. The object of this paper is to generalize these results of Libera and Livingston by choosing instead of $S^{*}$ the class $S^{*}(\alpha)$ of starlike functions of order $\alpha$ and replacing the definition of $F(z)$ in (1) by

$$
F(z)=\frac{2}{g(z)} \int_{0}^{z} f(t) d t
$$

where $f(z)$ and $g(z)$ are starlike functions of orders $\alpha$ and $\gamma$ respectively. Extensions of the results of Libera and Livingston in other directions were made by Padmanabhan [6], Nikolaéva and Repniná, [5], Bernardi [1].

THeOREM 1. If $f(z) \in S^{*}(\alpha)$ and $g(z) \in S^{*}(\gamma)$, then the function $F(z)$ defined by 


$$
F(z)=\frac{2}{g(z)} \int_{0}^{z} f(t) d t
$$

is $\beta$-starlike for $|z|<\sigma=\sigma(\alpha, \beta, \gamma)$ where $\sigma$ is given by

$$
\begin{aligned}
& \sigma[1+2 \alpha-2 \gamma-\beta] \\
& \quad=\left[(2-\alpha-\gamma)^{2}+(1-\beta)(1+2 \alpha-2 \gamma-\beta)\right]^{1 / 2}-(2-\alpha-\gamma)
\end{aligned}
$$

when $1+2 \alpha-2 \gamma-\beta \neq 0,2 \sigma(2-\alpha-\gamma)=1-\beta$ when $\beta=1+$ $2 \alpha-2 \gamma$.

Proof. Let $P(\alpha)$ denote the class of all regular functions $p(z)$ in $E$ which satisfy the conditions $p(0)=1, \operatorname{Re}[p(z)]>\alpha(0 \leqq \alpha<1)$. Examining the proof of Lemma 1 in [2] we easily find that if $N$ and $D$ are regular in $E, N(0)=D(0)=0, D$ maps $E$ onto a many-sheeted region which is starlike with respect to origin and $N^{\prime} / D^{\prime} \in P(\alpha)$, then $N / D \in P(\alpha)$. Further we note that

$$
\sigma(z)=\int_{0}^{z} f(t) d t
$$

where $f(z) \in S^{*}(\alpha)$, is 2-valently starlike with respect to origin by [2, Lemma 2]. Now $F(z)=2 \sigma(z) / g(z)$ where $\sigma(z)=\int_{0}^{z} f(t) d t$. So,

$$
\begin{aligned}
z F^{\prime \prime}(z) / F(z) & =\left(z \sigma^{\prime}(z) / \sigma(z)\right)-\left(z g^{\prime}(z) / g(z)\right) \\
& =\left(z \sigma^{\prime}(z)-\sigma(z)\right) / \sigma(z)+1-\left(z g^{\prime}(z) / g(z)\right),
\end{aligned}
$$

$\sigma(z)$ being 2-valently starlike. If we choose $N(z)=z \sigma^{\prime}(z)-\sigma(z)$, $D(z)=\sigma(z)$, then $N^{\prime} / D^{\prime}=z \sigma^{\prime \prime}(z) / \sigma^{\prime}(z)=z f^{\prime}(z) / f(z)$ is a member of $P(\alpha)$. From the above observations we conclude that $\left\{z \sigma^{\prime}(z)-\sigma(z)\right\} / \sigma(z)$ is also a member of $P(\alpha)$. Now, $g(z) \in S^{*}(\gamma)$ and so

$$
\operatorname{Re}\left[\frac{z F^{\prime \prime}(z)}{F(z)}\right] \geqq 1+\frac{1+(2 \alpha-1) r}{1+r}-\frac{1-(2 \gamma-1) r}{1-r},
$$

since $p(z)=z f^{\prime}(z) / f(z) \in P(\alpha)$ implies $\operatorname{Re}[p(z)] \geqq(1+(2 \alpha-1) r) /(1+r)$ on $|z|=r$, by a known result. Thus $\operatorname{Re}\left[z F^{\prime \prime}(z) / F(z)\right] \geqq \beta$ on $|z|=r$ and hence $F(z)$ will be $\beta$-starlike for $|z|<r$, if

$$
1+\frac{1+(2 \alpha-1) r}{1+r}-\frac{1-(2 \gamma-1) r}{1-r} \geqq \beta .
$$

This condition gives $r<\sigma$ where $\sigma$ is as given in Theorem 1 . Theorem 1, together with the fact that every convex function is a starlike function of order $1 / 2$, implies the following corollary.

COROLlaRY. If $f(z) \in S^{*}(\alpha)$ and $g(z)$ is a convex univalent func- 
tion in $E$, then the function

$$
F(z)=\frac{2}{g(z)} \int_{0}^{z} f(t) d t
$$

is $\beta$-starlike for $|z|<\sigma\left(\alpha, \beta, 2^{-1}\right)$.

The limiting case $\gamma \rightarrow 1$ while $\alpha=\beta=0$ gives the result of Libera [2].

Before proving our main theorem on a partial converse of Theorem 1, we prove two elementary lemmas which are important for our considerations.

Lemma 1. Suppose $p(z)=[1+D w(z)][1+B w(z)]^{-1}$ where $w(z)$ is regular in $E, w(0)=0,|w(z)|<1$ for $z \in E$ and $-1 \leqq D<B \leqq 1$; then for any $C \geqq B$, we have on $|z|=r<1$,

$$
\begin{aligned}
\operatorname{Re} & {\left[C p(z)+\frac{D}{p(z)}\right]-\left[\frac{r^{2}|B p(z)-D|^{2}-|1-p(z)|^{2}}{\left(1-r^{2}\right)|p(z)|}\right] } \\
& \geqq\left\{\begin{array}{l}
P_{1}(r) \text { for } R_{0} \leqq R_{1}, \\
P_{2}(r) \text { for } R_{0} \geqq R_{1},
\end{array}\right.
\end{aligned}
$$

where

$$
\begin{gathered}
P_{1}(r)=C\left(\frac{1+D r}{1+B r}\right)+D\left(\frac{1+B r}{1+D r}\right) \\
P_{2}(r)=\frac{2}{\left(1-r^{2}\right)}\left\{( 1 + D ) ^ { 1 / 2 } \left[1+C-\left(D(1+C)+B^{2}+C\right) r^{2}\right.\right. \\
\left.\left.+D\left(B^{2}+C\right) r^{4}\right]^{1 / 2}-\left(1-B D r^{2}\right)\right\} \\
R_{0}^{2}=\frac{(1+D)\left(1-D r^{2}\right)}{(1+C)-r^{2}\left(C+B^{2}\right)}
\end{gathered}
$$

and

$$
R_{1}=\frac{1+D r}{1+B r}
$$

Proof. A hint for the following proof is in [7]. $p(z)$ is subordinate to the linear fractional transformation $(1+A z) /(1+B z)$ and from this it follows by elementary arguments that

$$
|p(z)-a| \leqq d,
$$

where 


$$
a=\frac{1-B D r^{2}}{1-B^{2} r^{2}}, \quad d=\frac{(B-D) r}{1-B^{2} r^{2}} .
$$

If $p(z)=a+u+i v$ with $a$ as defined above and $R^{2}=|p(z)|^{2}=$ $(a+u)^{2}+v^{2}$, then by a simple computation

$$
\begin{aligned}
\operatorname{Re} & {\left[C p(z)+\frac{D}{p(z)}\right]-\left\{\frac{r^{2}|B p(z)-D|^{2}-|1-p(z)|^{2}}{\left(1-r^{2}\right)|p(z)|}\right\} } \\
& =C(a+u)+\frac{D(a+u)}{R^{2}}+\frac{\left(1-B^{2} r^{2}\right)\left(u^{2}+v^{2}-d^{2}\right)}{\left(1-r^{2}\right) R} \\
& \equiv S(u, v), \text { say } .
\end{aligned}
$$

Then

$$
\frac{\partial S(u, v)}{\partial v}=v R^{-4} T(R)
$$

where

$$
\begin{aligned}
T(R)= & -2 D(a+u)+2 R^{3}\left(1-r^{2}\right)^{-1}\left(1-B^{2} r^{2}\right) \\
& +R\left(1-r^{2}\right)^{-1}\left(1-B^{2} r^{2}\right)\left(d^{2}-u^{2}-v^{2}\right) .
\end{aligned}
$$

Evidently,

$$
T(R) \geqq 2(a+u)\left[\left(\frac{1-B^{2} r^{2}}{1-r^{2}}\right)(a-d)^{2}-D\right] \geqq 0,
$$

since $R \geqq a+u \geqq a-d$, as is easily verified. Thus $S(u, v)$, as a function of $v$, attains its minimum when $v=0$ and the minimum value is given by

$$
\begin{aligned}
\operatorname{Min}_{v} S(u, v)= & S(u, 0) \equiv L(R)=C R+\frac{D}{R} \\
& +\left(\frac{1-B^{2} r^{2}}{1-r^{2}}\right) \frac{1}{R}\left[R^{2}+a^{2}-2 a R-d^{2}\right],
\end{aligned}
$$

since $v=0$ implies $a+u=R$. The absolute minimum of $L(R)$ is attained at $R=R_{0}=(\mathrm{m} / \mathrm{l})^{1 / 2}$, where

$$
\begin{gathered}
m=D+\left(1-r^{2}\right)^{-1}\left(a^{2}-d^{2}\right)\left(1-B^{2} r^{2}\right), \\
l=C+\left(1-r^{2}\right)^{-1}\left(1-B^{2} r^{2}\right) .
\end{gathered}
$$

However, since $a-d \leqq R \leqq a+d, R$ takes the value $R_{0}$ only when $a-d \leqq R_{0} \leqq a+d$. It can be verified that $R_{0} \leqq a+d$, while $R_{0}$ may not always be greater than $(a-d)$. Further if $R_{0}<a-d \leqq R$, then $R_{0}^{2}=m / l<R^{2}$ and so $L(R)$ is a monotonic increasing function of $R$. Thus $L(R)$ attains its minimum $L(a-d)$ at $R=a-d$. A computation shows that $L(a-d)=P_{1}(r)$ and $L\left(R_{0}\right)=P_{2}(r)$ where 
$P_{1}(r)$ and $P_{2}(r)$ are as defined in Lemma 1. This completes the proof of Lemma 1.

Lemma 2. If $w(z)$ is regular in $E$ and satisfies $|w(z)| \leqq|z|$ for $z \in E$ and $p(z)=[1+D w(z)][1+B w(z)]^{-1}$, then

$$
\begin{aligned}
\operatorname{Re}\left\{\frac{z w^{\prime}(z)}{[1+B w(z)][1+D w(z)]}\right\} \leqq & -\frac{1}{(B-D)^{2}}\left\{\operatorname{Re}\left[\frac{D}{p(z)}+B p(z)\right]\right. \\
& -\left[\frac{r^{2}|B p(z)-D|^{2}-|1-p(z)|^{2}}{\left(1-r^{2}\right)|p(z)|}\right] \\
& -(B+D)\}
\end{aligned}
$$

Proof. $\Phi(z)=z^{-1} w(z)$ satisfies $|\Phi(z)| \leqq 1$ in $E$ and so by a wellknown result, we have,

$$
\left|\Phi^{\prime}(z)\right| \leqq\left(1-|\Phi(z)|^{2}\right)\left(1-|z|^{2}\right)^{-1} .
$$

Thus using $\Phi(z)=z^{-1} w(z)$, we get

$$
\left|z w^{\prime}(z)-w(z)\right| \leqq\left(r^{2}-|w(z)|^{2}\right)\left(1-r^{2}\right)^{-1} .
$$

So we have on $|z|=r$,

$$
\begin{aligned}
\operatorname{Re}\left\{\frac{z w^{\prime}(z)}{[1+B w(z)][1+D w(z)]}\right\} \leqq & \operatorname{Re}\left\{\frac{w(z)}{[1+D w(z)][1+B w(z)]}\right\} \\
& +\left\{\frac{r^{2}-|w(z)|^{2}}{\left(1-r^{2}\right)|1+D w(z)||1+B w(z)|}\right\} .
\end{aligned}
$$

A simple computation using $w(z)=(1-p(z))(B p(z)-D)^{-1}$, gives the inequality stated in Lemma 2.

THEOREM 2. Let $g(z) \in S^{*}(\gamma)$ and $F(z) \in S^{*}(\alpha)$ and define $f(z)$ by

$$
F(z) g(z)=2 \int_{0}^{z} f(t) d t
$$

or, equivalently, by

$$
f(z)=2^{-1}(g(z) F(z))^{\prime},
$$

then for $|z|=r$,

$$
\operatorname{Re}\left[\frac{z f^{\prime}(z)}{f(z)}\right] \geqq\left\{\begin{array}{l}
P_{1}(r) \text { for } R_{0} \leqq R_{1}, \\
P_{2}(r) \text { for } R_{0} \geqq R_{1},
\end{array}\right.
$$

where 


$$
\begin{aligned}
P_{1}(r) & =\frac{1}{(1-A)}\left\{\left[(3-2 A)\left[\frac{1+A r}{1+r}\right]+A\left[\frac{1+r}{1+A r}\right]-2\right\},\right. \\
P_{2}(r) & =\frac{2}{1-A}\left\{\left[\frac{(1+A)(4-2 A))\left(1-A r^{2}\right)}{1-r^{2}}\right]^{1 / 2}-\left[\frac{7-A r^{2}}{1-r^{2}}\right]-1\right\}, \\
R_{0}^{2} & =(1+A)\left(1-A r^{2}\right) /(4-2 A)\left(1-r^{2}\right), \\
R_{1} & =(1+A r) /(1+r),
\end{aligned}
$$

and

$$
A=\alpha+\gamma-1
$$

These bounds are sharp.

$$
\text { Proof. } 2 f(z)=g(z) F^{\prime}(z)+F(z) g^{\prime}(z) .
$$

So

$$
\frac{2 z f(z)}{g(z) F(z)}=\frac{z F^{\prime}(z)}{F(z)}+\frac{z g^{\prime}(z)}{g(z)}
$$

$F(z) \in S^{*}(\alpha)$ and $g(z) \in S^{*}(\gamma)$ imply that $z F^{\prime}(z) / F(z) \in P(\alpha)$ and $z g^{\prime}(z) / g(z) \in P(\gamma)$. Thus $z f(z) / g(z) F(z) \in P((\alpha+\gamma) / 2)$ and so, by a well-known representation formula, we have

$$
\frac{z f(z)}{g(z) F(z)}=\frac{1+A w(z)}{1+w(z)}
$$

where $A=\alpha+\gamma-1$ and $w(z)$ is regular in $E$ and satisfies $|w(z)| \leqq|z|$ for $z \in E$. Let $p(z)=[1+A w(z)][1+w(z)]^{-1}$, then we have

$$
z f(z)=g(z) F(z) p(z) \text {. }
$$

Thus,

$$
\begin{aligned}
\frac{z f^{\prime}(z)}{f(z)} & =\frac{z g^{\prime}(z)}{g(z)}+\frac{z F^{\prime}(z)}{F(z)}+\frac{z p^{\prime}(z)}{p(z)}-1 \\
& =2 p(z)+\frac{z p^{\prime}(z)}{p(z)}-1,
\end{aligned}
$$

using (3) and (4). Now,

$$
\frac{z p^{\prime}(z)}{p(z)}=\frac{-(1-A) z w^{\prime}(z)}{[1+A w(z)][(1+w(z)]} .
$$

An application of Lemma 2 and then Lemma 1 with $C=3-2 A$, $B=1$ and $D=A$ gives immediately the inequality stated in Theorem 2 . We now show that the bounds are sharp. Let us choose $g_{1}(z) \in$ $S^{*}(\gamma)$ and $F_{1}(z) \in S^{*}(\alpha)$ defined by the formulas, 


$$
\frac{z g_{1}^{\prime}(z)}{g_{1}(z)}=\frac{1+(2 \gamma-1) w_{1}(z)}{1+w_{1}(z)}, \frac{z F_{1}^{\prime}(z)}{F_{1}(z)}=\frac{1+(2 \alpha-1) w_{1}(z)}{1+w_{1}(z)} .
$$

The corresponding $f_{1}(z)=2^{-1}\left(g_{1}(z) F_{1}(z)\right)^{\prime}$ satisfies

$$
p_{1}(z)=\frac{z f_{1}(z)}{g_{1}(z) F_{1}(z)}=\frac{1+A w_{1}(z)}{1+w_{1}(z)}, \quad A=\alpha+\gamma-1 .
$$

From the proof of Lemma 1 it is evident that the bounds $P_{1}(r)$ and $P_{2}(r)$ will be attained only when $R=a-d$ and $R=R_{0}$ respectively, where $R=|p(z)|=\operatorname{Re} p(z)$. Since $a-d=(1+A r) /(1+r)$, the function $w_{1}(z) \equiv z$ will give $g_{1}(z), F_{1}(z)$ such that $\left|p_{1}(z)\right|=\operatorname{Re} p_{1}(z)=$ $a-d$ at $z=r$ and so the bound $P_{1}(r)$ will be attained by the corresponding function $z f_{1}^{\prime}(z) / f_{1}(z)$, at $z=r$, for all $r$ satisfying $R_{0} \leqq R_{1}$. When $R_{0} \geqq R_{1}=a-d$, we choose $w_{2}(z)=z(z-q) /(1-q z)$ where $q$ is determined by the condition that $p_{2}(z)=\left(1+A w_{2}(z)\right) /\left(1+w_{2}(z)\right)$ satisfies $\left|p_{2}(z)\right|=R_{0}=\operatorname{Re} p_{2}(z)$ at $z=r$. Now we have

$$
a-d=R_{1} \leqq R_{0} \leqq a+d,
$$

so

$$
\frac{1+A r}{1+r} \leqq \frac{1+A T}{1+T} \leqq \frac{1-A r}{1-r},
$$

where $T=w_{2}(r)$ and this in turn implies one of the three following equivalent conditions,

$$
\begin{aligned}
\frac{r^{2}(r-q)^{2}}{(1-q r)^{2}} & =T^{2} \leqq r^{2}, \\
q^{2} & \leqq 1, \\
|q| & \leqq 1 .
\end{aligned}
$$

So $w_{2}(z)$ is indeed subordinate to $z$ in $E$ and hence $p_{2}(z)$ belongs to $P((\alpha+\gamma) / 2)$. Clearly, $g_{2}(z) \in S^{*}(\gamma)$ and $F_{2}(z) \in S^{*}(\alpha)$ defined by the formulas

$$
\frac{z g_{2}^{\prime}(z)}{\mathrm{g}_{2}(z)}=\frac{1+(2 \gamma-1) w_{2}(z)}{1+w_{2}(z)}, \frac{z F_{2}^{\prime}(z)}{F_{2}(z)}=\frac{1+(2 \alpha-1) w_{2}(z)}{1+w_{2}(z)}
$$

give rise to $f_{2}(z)$ which satisfies $\left|p_{2}(r)\right|=\operatorname{Re} p_{2}(r)=R_{0}$, where

$$
p_{2}(z)=\frac{z f_{2}(z)}{g_{2}(z) F_{2}(z)}=\frac{1+A w_{2}(z)}{1+w_{2}(z)},
$$

and so $z f_{2}^{\prime}(z) / f_{2}(z)$ attains the bound $P_{2}(r)$ at $z=r$.

THEOREM 3. If the family $Q$ is defined by 


$$
Q=\left\{f(z)=2^{-1}(g(z) F(z))^{\prime} ; g(z) \in S^{*}(\gamma), F(z) \in S^{*}(\alpha) \text { and } \alpha+\gamma \leqq 1\right\},
$$

then the radius of $\beta$-starlikeness of the family $Q$ is the least positive root of the equation $P_{1}(r)-\beta=0$, where $P_{1}(r)$ is as defined in Theorem 2.

Proof. By Theorem 2, the minimum of $\operatorname{Re}\left(z f^{\prime}(z) / f(z)\right)$ for $f$ belonging to $Q$ is $P_{1}(r)$ for all $|z|=r$ satisfying $R_{0} \leqq R_{1}$. Thus, for $R_{0} \leqq R_{1}$, the requirement that $f(z)$ be $\beta$-starlike for $|z|<r$ gives the condition on $r$ as $P_{1}(r)-\beta \geqq 0$. This condition will be true for all values of $r<\sigma$ where $\sigma$ is the least positive root of the equation $P_{1}(r)-\beta=0$, since $P_{1}(0)-\beta>0$ for all $\beta \in[0,1)$. It remains to verify that $\sigma$ also satisfies the condition

$$
\left(R_{0}\right)_{r=\sigma} \leqq\left(R_{1}\right)_{r=\sigma} \text {. }
$$

For this we note that $R_{0}^{2}=(1+A)\left(1-A r^{2}\right) /\left(1-r^{2}\right)(4-2 A)$ and so

$$
2 \frac{d R_{0}}{d r}=\frac{\left(1-A^{2}\right) 2 r}{\left(1-r^{2}\right)^{2}(4-2 A)} \geqq 0 \text {. }
$$

Thus $R_{0}$ is an increasing function of $r$. Moreover $R_{1}=(1+A r) /(1+r)$ implies

$$
\frac{d R_{1}}{d r}=-\frac{(1-A)}{(1+r)^{2}}<0
$$

and so $R_{1}$ is a decreasing function of $r$. Thus the equation $R_{0}-R_{1}=0$ has at the most one root in $(0,1]$. The inequality $R_{0}-R_{1} \leqq 0$ holds if and only if

$$
T(r) \equiv A(1-2 A) r^{3}+A(2 A-7) r^{2}+(4 A-5) r+3 \geqq 0 .
$$

Now $T(0)=3>0$ and $T(1)=-2(1+A) \leqq 0$ and so $R_{0}-R_{1}=0$ has at least one root in $(0,1]$. Let the unique root of the equation $T(r)=0$ be $r_{A}$. Thus the condition $R_{0} \leqq R_{1}$ holds for some $r$ if and only if $r \leqq r_{A}$. Thus $R_{0} \leqq R_{1}$ holds at $r=\sigma$ if and only if $\sigma \leqq r_{A}$. Now $P_{1}(r)-\beta$ satisfies $P_{1}(0)-\beta>0$. We show $P_{1}\left(r_{A}\right) \leqq 0$. This will imply that $P_{1}\left(r_{A}\right)-\beta \leqq 0$ and, in particular, that $\sigma$, the least positive root of the equation $P_{1}(r)-\beta=0$, will satisfy $\sigma \leqq r_{A}$. Now a calculation shows that

$$
P_{1}(r)=\frac{r^{2}\left(2 A^{2}-A\right)+r(4 A-2)+1}{1+(1+A) r+A r^{2}} .
$$

Therefore $P_{1}(r) \leqq 0$ if $r$ exceeds the least positive root of the equation

$$
x^{2}\left(2 A^{2}-A\right)+x(4 A-2)+1=0 .
$$


i.e., $P_{1}(r) \leqq 0$ if $r \geqq(1-t) / s$ where

$$
s=-A \geqq 0, \quad t=\left(\frac{1-A}{1-2 A}\right)^{1 / 2} .
$$

So $P_{1}\left(r_{A}\right) \leqq 0$ if $r_{A} \geqq(1-t) / s$. But $r_{A} \geqq(1-t) / s$ if and only if $T((1-t) / s) \geqq 0$, since $T(r)=0$ has a unique root in $(0,1]$ and $T(0)>0$. Changing $A$ to $-s$, we get the fact that $T(r) \geqq 0$ if and only if,

$$
-r^{3}(1+2 s) s+(2 s+7) s r^{2}-(4 s+5) r+3 \geqq 0 .
$$

Substituting $r=(1-t) / s$ and using elementary calculations, the condition reduces to

$$
-4 s\left(1-s^{2}\right)-4 s(1-s)-(2 s+1) \leqq 0 .
$$

Since $A=\alpha+\gamma-1 \leqq 0$ and $s=-A$, the last inequality is trivially true. Further, the bounds obtained in Theorem 2 are sharp and so the radius $\sigma$ obtained above is also sharp for the family $Q$ under consideration and this completes the proof of Theorem 3.

REMARKS. It should be noted that we have not used the full force of Lemma 1, in the proof of Theorem 3. Other conditions on $F(z)$ and $g(z)$ such as

$$
\left|\frac{z F_{1}^{\prime}(z)}{F_{1}(z)}-1\right|\left|\frac{z F_{1}^{\prime}(z)}{F_{1}(z)}+1\right|^{-1}<\alpha \quad 0<\alpha \leqq 1,
$$

or

$$
\left|\frac{z F_{1}^{\prime}(z)}{F_{1}(z)}-\alpha\right|<\alpha \quad \alpha>\frac{1}{2}
$$

or

$$
\left|\frac{z F_{1}^{\prime}(z)}{F_{1}(z)}-1\right|<\alpha \quad 0<\alpha \leqq 1
$$

where $F_{1}(z)=(g(z) F(z))^{1 / 2} ; F_{1}(0)=1$, could be considered instead of $F_{1}(z)$ being in $S^{*}((\alpha+\gamma) / 2)$ as in Theorem 3. Problems with these conditions can be solved similarly by choice of suitable values for $A, B, C$ in Lemma 1. Also the case $\alpha+\gamma>1$ left out in the theorem can be treated using the above estimates. Details relating to this case which involve difficult calculations will be published on another occasion. Further, from Theorem 3, it follows that if $\alpha+\gamma=1$, the radius of $\beta$-starlikeness of the family $Q$ is given by $\sigma=(1-\beta) /(2+\beta)$ and this is a slight generalization of [3, Corollary 2 to Theorem 1]. The author would like to thank Professor K. S. Padmanabhan for 
helpful discussions. He also thanks a referee who suggested a better presentation of the material.

\section{REFERENCES}

1. S. D. Bernardi, The radius of univalence of certain analytic functions, Proc. Amer. Math. Soc., 24 (1970), 312-318.

2. R. J. Libera, Some classes of regular univalent functions, Proc. Amer. Math. Soc., 16 (1965), 755-758.

3. R. J. Libera and A. E. Livingston, On the univalence of some classes of regular functions, Proc. Amer. Math, Soc., 30 (1971), 322-336.

4. A. E. Livingston, On the radius of univalence of certain analytic functions, Proc. Amer. Math. Soc., 17 (1966). 352-357.

5. R. V. Nikolaéva and L. G. Repniná, A certain generalization of theorems due to Livingston, Ukrain. Mat. Ž., 24 (1972), 268-273 (Russian).

6. K. S. Padmanabhan, On the radius of univalence of certain classes of analytic functions, J. London. Math. Soc., (2) 1 (1969), 225-231.

7. V. Singh and R. M. Goel, On radii of convexity and starlikeness of some classes of functions, J. Math. Soc. Japan, 23 (1971), 323-339.

Received April 14, 1975 and in revised form July 22, 1975.

The Ramanujan Institute

UNIVERSITY OF MADRAS

MADRAS-600 005, INDIA. 


\section{PACIFIC JOURNAL OF MATHEMATICS}

\section{EDITORS}

RICHARD ARENS (Managing Editor) University of California

Los Angeles, California 90024

\section{R. A. BEAUMONT}

University of Washington Seattle, Washington 98105
J. DugundjI Department of Mathematics University of Southern Californı Los Angeles, California 90007

D. Gilbarg AND J. Milgram Stanford University Stanford, California 94305

\section{ASSOCIATE EDITORS}

E. F. BECKENBACH

B. H. NeUMANN

F. WOLF

K. YosHidA

\section{SUPPORTING INSTITUTIONS}

UNIVERSITY OF BRITISH COLUMBIA CALIFORNIA INSTITUTE OF TECHNOLOGY UNIVERSITY OF CALIFORNIA MONTANA STATE UNIVERSITY UNIVERSITY OF NEVADA NEW MEXICO STATE UNIVERSITY OREGON STATE UNIVERSITY UNIVERSITY OF OREGON OSAKA UNIVERSITY

\author{
UNIVERSITY OF SOUTHERN CALIFORNIA \\ STANFORD UNIVERSITY \\ UNIVERSITY OF TOKYO \\ UNIVERSITY OF UTAH \\ WASHINGTON STATE UNIVERSITY \\ UNIVERSITY OF WASHINGTON \\ AMERICAN MATHEMATICAL SOCIETY \\ NAVAL WEAPONS CENTER
}




\section{Pacific Journal of Mathematics}

\section{Vol. 61, No. $1 \quad$ November, 1975}

Jiří Adámek, V. Koubek and Věra Trnková, Sums of Boolean spaces represent every

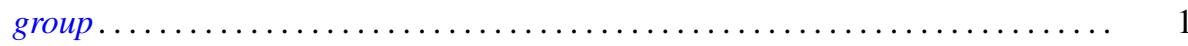

Richard Neal Ball, Full convex l-subgroups and the existence of $a^{*}$-closures of

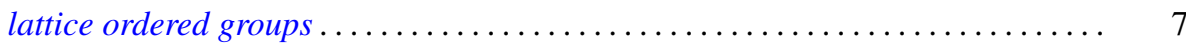

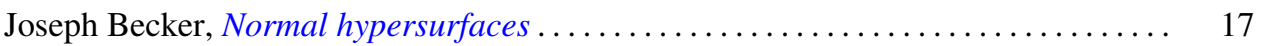

Gerald A. Beer, Starshaped sets and the Hausdorff metric . . . . . . . . . . . . . 21

Dennis Dale Berkey and Alan Cecil Lazer, Linear differential systems with

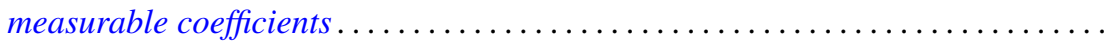

Harald Boehme, Glättungen von Abbildungen 3-dimensionaler

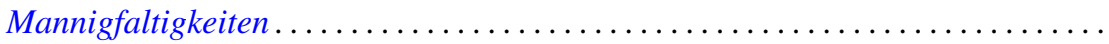

Stephen LaVern Campbell, Linear operators for which $T^{*} T$ and $T+T^{*}$

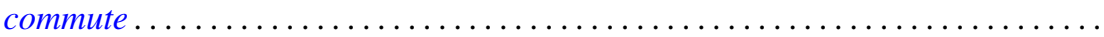

H. P. Dikshit and Arun Kumar, Absolute summability of Fourier series with

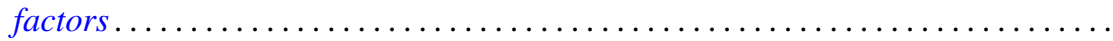

Andrew George Earnest and John Sollion Hsia, Spinor norms of local integral

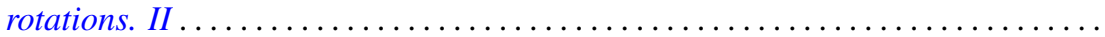

Erik Maurice Ellentuck, Semigroups, Horn sentences and isolic structures .........

Ingrid Fotino, Generalized convolution ring of arithmetic functions . . . . . . . . . . .

Michael Randy Gabel, Lower bounds on the stable range of polynomial rings .......

Fergus John Gaines, Kato-Taussky-Wielandt commutator relations and

characteristic curves

Theodore William Gamelin, The polynomial hulls of certain subsets of $C^{2}$

R. J. Gazik and Darrell Conley Kent, Coarse uniform convergence spaces. . .

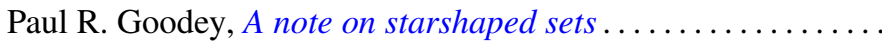

Eloise A. Hamann, On power-invariance

M. Jayachandran and M. Rajagopalan, Scattered compactification for $N \cup\{P\}$. . .

V. Karunakaran, Certain classes of regular univalent functions .

John Cronan Kieffer, A ratio limit theorem for a strongly subadditive set function in a locally compact amenable group .................

Siu Kwong Lo and Harald G. Niederreiter, Banach-Buck measure, density, and uniform distribution in rings of algebraic integers ........

Harold W. Martin, Contractibility of topological spaces onto metric spaces ....

Harold W. Martin, Local connectedness in developable spaces .

A. Meir and John W. Moon, Relations between packing and covering numbers of a tree.

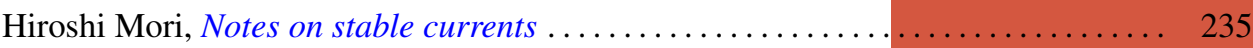

Donald J. Newman and I. J. Schoenberg, Splines and the logarithmic function . . . . 241

M. Ann Piech, Locality of the number of particles operator....

Fred Richman, The constructive theory of $K T$-modules .......

Gerard Sierksma, Carathéodory and Helly-numbers of

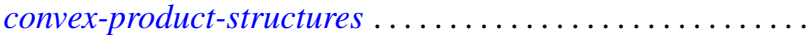

Raymond Earl Smithson, Subcontinuity for multifunctions .... . . 